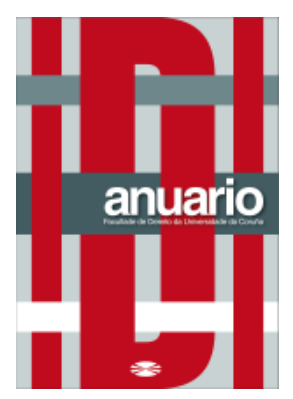

Anuario da Facultade de Dereito da Universidade da Coruña

Vol. 23 (2019), pp. 27-49

ISSNe: 2530-6324 || ISSN: 1138-039X

DOI: https://doi.org/10.17979/afdudc.2019.23.0.6010

\title{
LAS FUNCIONES DEL CONGRESO MEXICANO
}

\section{THE POWERS OF THE MEXICAN CONGRESS}

\begin{abstract}
CÉSAR CAMACHO QUIROZ
Presidente de El Colegio Mexiquense

Investigador del Centro de Investigación en Ciencias Jurídicas, Justicia Penal y Seguridad

Pública. UAEMex.

CARLOS MUÑIZ DÍAZ

Investigador del Centro de Investigación en Ciencias Jurídicas, Justicia Penal y Seguridad

Pública. UAEMex.

Miembro del Sistema Nacional de Investigadores Nivel I
\end{abstract}

Resumen: En el presente artículo se exponen las funciones del Congreso Mexicano a la luz de la teoría sociológica del funcionalismo de Bronislaw Malinowski, basada en los conceptos de necesidad y función. Aplicada dicha teoría al análisis del Poder Legislativo se comprenden mejor las necesidades que cada función satisface: la representativa, legislativa, financiera y de control, al menos. Con su ejercicio, fortalece la vida democrática y el estado de derecho; y se destaca el papel del Legislativo como instancia de equilibrio, de fiscalización y control indispensable en un sistema plural y diverso que acrecienta su legitimidad por el origen popular de sus miembros y por el ejercicio democrático de sus atribuciones. Mucho más, a diferencia del Ejecutivo es colegiado y, contrario al Judicial, es plural, lo cual lo convierte en el summum de la representación nacional.

Palabras clave: Congreso mexicano, funciones, Constitución, democracia, representación.

Abstract: The article presents Mexico's Congress powers from the sociological theory named "functionalism" created by Bronislaw Malinowski, based on the concepts of need and function. When applied to the study of the Legislative branch, this theory allows us to better understand the social and political needs each power satisfies. The representation as a general responsibility can be developed into legislative, financial or oversight powers, among others. The current execution of this tasks strengthen democratic life and the rule of law. Within this framework, the Legislative branch is highlighted as an indispensable equilibrium-achieving, oversight and impeach entity, because of its essentially democratic 
nature, manifested in the popular-elected origins of senators and representatives, but in how it exercises its responsibilities and powers. Much more, unlike the Executive branch, the Legislative one has a collective character, and unlike the Judicial one, it is plural, a feature that makes of it, the ultimate recipient of national representation.

Keywords: Mexican Congress, powers, Constitution, democracy, representation.

Sumario: I. INTRODUCCIÓN. II. FUNCIONES DEL CONGRESO. 1. La función representativa. 2. La función legislativa. 3. La función financiera. A. El Paquete económico. 4. La función de control. A. Control político. B. Juicio político. C. El informe del Ejecutivo y las comparecencias. D. Comisiones de investigación. E. Nombramientos y ratificaciones. F. Cuestión política. G. Desaparición de poderes en los Estados. H. Tratados internacionales. I. Otros mecanismos de control político. J. Control económico. K. Evaluación de la gestión financiera. 5. Funciones de carácter instrumental. A. La función deliberativa. B. La función jurisdiccional. C. La función parlamentaria administrativa. III. CONCLUSIONES. IV. FUENTES DE CONSULTA.

\section{INTRODUCCION}

Parece una obviedad, pero en cualquier estado democrático el poder público es una manifestación de la voluntad general la cual dicta, siempre, que dicho poder debe incidir positivamente en la vida de las personas.

En el mundo occidental, la referida voluntad general se debe verter en una Constitución, formal y materialmente hablando, la que, en todo caso, debe contener, al menos, el reconocimiento y protección de los derechos fundamentales, así como la organización elemental del mencionado poder público; esto es, el desarrollo y "desdoblamiento" de todas las expresiones de la autoridad que en su integración y desempeño deberá ceñirse a la decisión fundacional y, en la vida cotidiana, habrá de producir actos jurídicos y operaciones materiales para cumplir los fines superiores del Estado, para cuya consecución deberá tenerse presente la pretensión secular de alcanzar la felicidad de la comunidad.

Independientemente de la adopción de alguna de las formas de estado o de gobierno; o sea, de la organización política y territorial o de la preponderancia de algún poder sobre los otros, los estados modernos deben sujetarse a la Constitución y garantizar que el acceso y ejercicio del poder sean democráticos.

Desde 1824 nuestra Nación tomó las posteriormente denominadas decisiones políticas fundamentales: ser una república representativa, popular y federal, y con todo y los avatares decimonónicos resultado del embate centralista e imperial, el país se ha mantenido razonablemente fiel a aquéllas, que revelan un modo de ser colectivo. 
De esa suerte, el Estado mexicano desarrolla diversas actividades con base en su poder y para justificar su propia existencia; lo hace a través de las bien conocidas funciones del Estado, nunca en interés de la autoridad sino del de la sociedad, que es el origen y fin del mismo, teniendo siempre al Derecho como cauce y dique de su actuación.

Desde el origen se adoptó la teoría de frenos y contrapesos, de manera que el poder se ha dividido "para su ejercicio, en Legislativo, Ejecutivo y Judicial" de modo que cada uno, con justificadas excepciones, desarrolla sendas funciones para evitar la concentración perniciosa del poder.

En este orden de ideas, el republicanismo, con un breve paréntesis, ha sido otra constante en el ejercicio del poder público; y éste se funda en la libertad e igualdad política y se erige sobre una base social homogénea que sirve para mantener el andamiaje institucional que da forma a la comunidad política; tiene lugar en el marco de un respeto generalizado a la ley, empezando por las autoridades, como debe ocurrir en un estado de derecho consolidado.

Todos los elementos citados son inherentes a la democracia y ésta puede considerarse como un conjunto de reglas que fija quien está autorizado a adoptar las decisiones colectivas y a establecer los procedimientos ${ }^{1}$. Contemporáneamente ésta es la representación democrática que toma luz de Rousseau cuando se refirió a esto como la "forma de resolver los problemas de muchos por unos cuantos"2; que hace posible el acceso democrático al poder mediante la elección de quienes toman las decisiones políticas y el ejercicio democrático del mismo, que se acredita al conseguir resultados socialmente apetecibles y rendir cuentas permanentemente. Es aquí donde se encuentra el origen, desarrollo y finalidad que debe cumplir el Poder Legislativo en un sistema democrático.

Representación y democracia están, pues, íntimamente relacionados y la expresión más acabada de su ejercicio está en las asambleas parlamentarias en las que, en un clima de libertad, es posible la manifestación de las ideas, la deliberación y la ulterior adopción de resoluciones con el voto de las mayorías, pero con respeto a las opiniones y en salvaguarda de los derechos de las minorías. Las leyes, decretos, acuerdos o cualesquiera decisiones son tomadas por una autoridad colegiada y plural, con el poder legal y legítimo que otorga la representación nacional.

\section{FUNCIONES DEL CONGRESO}

“Función”, según el Diccionario Universal de Términos Parlamentarios, es la “[...] acción propia de una persona, órgano o mecanismo; [...] en el campo de las ciencias sociales, [...] es la puesta en práctica continuada de unas actividades que se consideran

\footnotetext{
${ }^{1}$ Bobbio, N., El futuro de la democracia, cit. pos. Carbonell, M. y Salazar, P., en División de poderes y régimen presidencial en México, México, UNAM, 2006, p. 87.

${ }^{2}$ Cit. pos. Mora-Donatto, C., Temas selectos de derecho parlamentario, México, Universidad Anáhuac del Sur, Miguel Ángel Porrúa, 2001, p. 34.
} 
valiosas y pueden, y aún deben, ser proseguidas de modo sucesivo por tiempo indefinido. La función es la realización sucesiva de una serie de fines análogos”3.

Desde el punto de vista sociológico, entonces, el funcionalismo — de acuerdo con Bronislaw Malinowski ${ }^{4}$ - se sustenta de manera principal en la teoría del hombre y la adaptación progresiva de las instituciones a las funciones que les han sido encomendadas. Además de una teoría, el funcionalismo es también un método que provee bases científicas para el estudio de las prácticas de una cultura determinada y la forma en que dichas prácticas se realizan. "Por sus frutos los conoceréis", es el lema del funcionalismo, para el cual la función deriva de la necesidad que se pretende satisfacer, la cual da lugar a otras demandas derivadas y, por supuesto, a otras funciones. Las ideas de Malinowski acerca de estos requerimientos son esenciales en el esquema funcionalista, pues ambas -necesidad y función- están íntimamente relacionadas, en tanto que la segunda solo tiene razón de ser si satisface necesidades. En términos sociológicos, entonces, una función es la contribución de una institución para mantener la estructura social, y para el caso de presente artículo, la teoría del funcionalismo aplicada al análisis del Poder Legislativo resulta útil para comprender las necesidades que la función satisface, así como su organización y funcionamiento para tal fin.

En un principio, las asambleas parlamentarias - en sentido literal, "reuniones para hablar" - se establecieron para discutir y, posteriormente, tomar acuerdos y emitir normas con las cuales se construía el andamiaje jurídico para dar orientación y fundamento de gobierno a los asuntos públicos o de interés general. Esta descripción del parlamento se relaciona con lo descrito al respecto por Carl Schmitt: “el pueblo en su totalidad, era quien debería decidir, como habría ocurrido antiguamente cuando todos los miembros de una comunidad podían reunirse bajo el tilo de la aldea; pero hoy, por razones prácticas, resulta imposible que todos se reúnan al mismo tiempo en un lugar y tampoco es factible preguntar a todos acerca de cualquier detalle. En base a esto, es lógico servirse de una comisión electa, constituida por personas de confianza y eso es precisamente el parlamento” 5 .

El parlamento moderno, como órgano colegiado que refleja la complejidad de las sociedades contemporáneas y la heterogeneidad de sus miembros, ha venido incrementando, poco a poco, el número de sus funciones. Las originales asambleas deliberativas devinieron, por necesidad, en representativas. Al desarrollarse, fueron sumando tareas a la propiamente legislativa, la presupuestaria y, más tarde, la fiscalizadora del gasto público, hasta llegar a convertirse en indiscutibles y eficaces depositarias de la diversa y compleja voluntad general. Dichas asambleas son en la actualidad crisol de intereses, ideologías, necesidades y recursos para dar viabilidad a una nación, entendida como origen y destino común, y no solo como sinónimo de Estado o país, cuyas funciones $\mathrm{y}$ atribuciones, múltiples y variadas encuentran, todas, sustento en un principio fundamental: el de la representación. Para comprender sus alcances y objetivos es fundamental identificarlas y clasificarlas, en el entendido de que se trata de "[...] una tarea compleja [ya que] los parlamentos son considerados instrumentos políticos del principio de

\footnotetext{
${ }^{3}$ Mora Donatto, C., Temas selectos. op. cit., p. 9.

${ }^{4}$ Páez Díaz de León, op. cit., p. 279.

${ }^{5}$ Schmitt, C., Sobre el Parlamento, Madrid, Tecnos, 1996, p. 42.
} 
soberanía popular, misión que les confiere invariablemente el derecho y el deber de intervenir, de diversas maneras, en la conducción de los asuntos públicos, según el régimen en el que actúen y el grado de desarrollo político de cada pueblo"6.

Para ello, debe considerarse que una tipología estrictamente formal desbordaría, como ya se señaló al hacer referencia a las funciones del Estado, la normativa a la que se sujeta el Congreso, puesto que las funciones que este realiza podrían caber, al mismo tiempo, en clasificaciones distintas, e inclusive en subclasificaciones, conforme a las necesidades que se pretendan cubrir.

En este sentido, me parece que se puede proponer una clasificación que consiga precisar tanto su naturaleza material, es decir, la referida al objetivo perseguido o necesidad que satisfacen, y la formal o instrumental que atendería a los procedimientos o mecanismos utilizados para llevarla a cabo, atento al hecho de que todas las funciones podrían caber en más de un tipo de la clasificación. A partir de lo expuesto, las funciones parlamentarias convencionalmente, se clasifican en: a) representativa; b) legislativa; c) financiera; d) de control; e) de carácter instrumental.

\section{La función representativa}

Esta es la piedra angular del quehacer de las asambleas parlamentarias, en tanto parte del reconocimiento de que el pueblo es el titular del poder público, pero dada la complejidad de las sociedades modernas, no puede participar en la tarea de gobernar ni tomar las decisiones públicas de manera directa.

La representación política ha sido el resultado de un largo proceso histórico; anulada en sus inicios por el pretendido origen divino de los monarcas, dejaba fuera el derecho del pueblo a participar en la toma de las decisiones fundamentales del reino ${ }^{7}$. Cabe mencionar que Rousseau consideraba que la soberanía no puede ser representada, por la misma razón de ser inalienable, la cual consiste en la voluntad general y, la voluntad no se representa, es una o es otra. También consideraba que los diputados del pueblo no son ni pueden ser representantes, son comisarios y no pueden resolver nada definitivamente, "Toda ley que el pueblo en persona no ratifica, la consideraba nula" 8 .

Todos eran súbditos de la corona y no ciudadanos libres, aunque el sistema privilegiaba a ciertos grupos. Esta situación comenzó a modificarse de forma irreversible cuando el pueblo reclamó una intervención sustantiva en la toma de decisiones, hasta que el principio de igualdad de los ciudadanos y su derecho a organizar de manera libre su gobierno quedó formulado de manera formal, por primera vez, en la Declaración de Independencia norteamericana y pocos años después, en la Declaración Universal de los Derechos del Hombre y el Ciudadano, principio que sirvió de base para la organización

\footnotetext{
6 Diccionario Universal de Términos Parlamentarios, $2^{\mathrm{a}}$ ed., México, Instituto de Investigaciones Legislativas de la Cámara de Diputados, LVI Legislatura, 1998, voces: división de funciones, Berlín Valenzuela, F., p. 373.

${ }^{7}$ Kelsen, H., Esencia y valor de la Democracia, $2^{a}$ ed., Colofón, México, 2004, págs. 54 y ss.

${ }^{8}$ Rousseau, J.-J., El Contrato Social, Grandes Pensadores, Barcelona, 2004, págs. 33 y ss.
} 
política de las naciones que asumieron como forma de gobierno la de república democrática y representativa, cuyo sistema de gobierno habría de particularizarse a partir de las condiciones propias de cada país: su extensión territorial, su pasado, su tradición política, su cultura jurídica y su realidad económica y social. Cuatro principios fundamentales han acompañado a esas naciones desde entonces: a) la supremacía constitucional; b) la separación de poderes; c) la representación política: y d) la participación política.

El principio de supremacía constitucional fue esbozado en El Federalista, al referirse al papel de intérprete de la ley que correspondía a los tribunales, que lo diferenciaba del que correspondía al cuerpo legislativo “[...] si se dijere que el cuerpo legislativo por si solo es constitucionalmente el juez de sus propios derechos y que la interpretación que de ellos se haga es decisiva para los otros departamentos, es lícito responder que no puede ser ésta la presunción natural en los casos en que no se colija de disposiciones especiales de la Constitución”’9

La fórmula de la representación política fue concebida como la respuesta más racional para ejercer las funciones derivadas de la instauración del poder soberano, en el que los poderes del Estado son los órganos instrumentales, cuyos integrantes asumen obligaciones y responsabilidades frente al pueblo.

En los estados modernos, el mandato de los ciudadanos no es ya para proteger los intereses de una clase o de un estamento, sino para representar al pueblo en su conjunto, que es lo que da legitimidad (principio fundamental de la democracia) al Legislativo para realizar su función de crear normas, puesto que aquel "no puede ser obligado a obedecer otras leyes que no sean las dictadas por aquéllos que él ha escogido y autorizado para legislar” ${ }^{10}$. Me parece fundamental acotar que la legitimidad está íntimamente relacionada con la eficacia "por un lado, el abanico de intereses representados condiciona los contenidos de las políticas; por otro, cuanto más amplio ese abanicos mayores garantías existen sobre la calidad técnica de las decisiones, las normas y leyes”"11. Por lo tanto, la función representativa es la base de todas las demás: “[...] el Parlamento, que representa una sociedad que es plural en su estructura social, cultura, creencias, valores y opiniones políticas, tiene que cumplir una función de caja de resonancia y, si cabe, de receptor y canalizador de demandas, opiniones, peticiones e iniciativas políticas o legislativas de los ciudadanos y ciudadanas" 12 .

Representar significa sustituir a uno o hacer sus veces, de suerte que un representante debe hacer las veces de sus representados al atender de forma adecuada sus intereses y aspiraciones.

El principio de representación en México está consagrado en los artículos 39 y 41 de la Constitución. El primero establece que la soberanía reside esencial y originariamente

9 Hamilton, A., Madison, J. y Jay, J., en Federalista, LXXVIII. En http:// www.antorcha.net/biblioteca_virtual/derecho/federalista/51. html, [consultado 10/1/2010].

${ }^{10}$ Locke, J., Ensayo sobre el gobierno civil, cit. pos. Caminal Badia, M., Manual de Ciencia Política, España, Ed. Tecnos, 1999, p. 409.

${ }^{11}$ Ibidem, p. 428.

${ }^{12}$ Idem., p. 421. 
en el pueblo, y de acuerdo con el segundo de ellos, este la ejerce por medio de los poderes de la Unión. A fin de darle consistencia y eficacia a la función representativa, se han creado los partidos políticos como vehículo para acceder a las instancias del poder público; éstos actúan como agentes aglutinadores de ideologías e intereses de diversos sectores de la comunidad, e instrumentos para impulsar propuestas de solución a los problemas y acometer los desafíos de la comunidad en general. Según la Constitución, su objetivo es promover una mayor y mejor participación de la población en la vida política.

Los legisladores, en tanto representantes de la sociedad, son los responsables de diseñar y establecer el entramado jurídico e institucional que la calidad de vida en la que estén cubiertas, al menos, sus necesidades básicas.

\section{La función legislativa}

La función legislativa que realizan los parlamentos obedece a la necesidad de seguridad y certeza jurídicas, que los ciudadanos conozcan las reglas que los rigen como sociedad. La creación de leyes es una facultad congénita del Legislativo, que consiste en verter en textos breves, claros, precisos y coherentes, aquello que la costumbre o el propósito de ser de una nación han instituido o pretenden instituir como norma para regir conductas, en relaciones individuales o colectivas.

El alcance y objetivo de la ley se expresa de manera nítida en esta frase de Rousseau: "hubiera querido vivir y morir libre, es decir, de tal manera sometido a las leyes, que ni yo ni nadie hubiese podido sacudir el honroso yugo, ese yugo suave y benéfico que las más altivas cabezas llevan tanto más dócilmente cuanto que están hechas para no soportar otro alguno"13.

La ley es una de las expresiones más acabadas de la voluntad popular, es una manifestación soberana del Estado, y es también expresión del principio de separación de poderes puesto en acto, con base en el cual se determinó que todo lo relacionado con la emisión de normas de carácter general, abstracto y obligatorio correspondiera al Legislativo.

El Diccionario Universal de Términos Parlamentarios define a la ley, “desde el punto de vista puramente formal, [como] lo acordado por los órganos legislativos competentes, dentro del procedimiento legislativo prescrito", se pone el acento en el carácter político del que está imbuida -que se extiende necesariamente a su aspecto material, al afirmar que "ley es una norma jurídica en que el Estado se dirige a sus súbditos para fijar entre ellos y el mismo, los límites de lo permitido y lo que puede hacerse. Pues es una cualidad de toda ley en sentido material, el poner límites a la libertad personal en general y a la propiedad en especial”14.

\footnotetext{
${ }^{13}$ Rousseau, J.-J., Discurso sobre el origen de las desigualdades entre los hombres, Madrid, Calpe, 1923, p. 2.

${ }^{14}$ Diccionario Universal de Términos Parlamentarios, op. cit., voz: Namorado Urrutia, P., p. 578.
} 
Con base en esta función, el Congreso elabora las leyes que permiten instrumentar los mandatos constitucionales, al interpretarlos en medio de un todo organizado y sistemático para facilitar el ejercicio efectivo de los derechos de toda naturaleza y dar respuesta a las distintas expresiones sociales; busca no solamente resolver los problemas existentes, sino también normar la conducta de los ciudadanos para evitar, bien que tales problemas vuelvan a presentarse o para tener a la mano una solución a los que surjan.

La ley, como expresión democrática, debe ser clara, a fin de que todos puedan entenderla, además de ser general y cierta, lo que abona al principio de seguridad jurídica; es uno de los pilares de los gobiernos democráticos.

La ley posee los mismos rasgos distintivos que se atribuyen al órgano que la produce, pues en su elaboración participan todos los grupos parlamentarios, si bien la decisión final, es claro, queda en manos de la mayoría, las minorías tienen derecho al debate, a expresar votos particulares y a dejar constancia de su posición al respecto y, eventualmente, a impugnarla ante la Corte, por suponerla inconstitucional. La actividad legislativa se concreta en la elaboración de normas jurídicas y es la conclusión de un proceso político en el que participan diversos grupos de presión, sindicatos, partidos, por el bien de sus propios intereses ${ }^{15}$, además de los poderes Legislativo y Ejecutivo. José Ortega y Gasset ha dicho que la ley tiene que suscitar nuevas realidades, que tiene que ser cada vez más creadora, que, todo derecho es un proyecto de futuro y que la función legislativa es una de las fuentes que generan el derecho ${ }^{16}$.

\section{La función financiera}

Se trata de "una importante actividad del parlamento relacionada a los aspectos generales y concretos de la Hacienda Pública y de la economía de un país”17. Vista en sentido amplio, la función financiera tiene que ver no solo con la aprobación de los ingresos y los egresos públicos, sino también con la vigilancia del ejercicio de estos últimos, la manera en que el gasto público se aplica y si se ajusta o no a los parámetros autorizados por el primero.

La fiscalización del gasto es, en sentido estricto, una función de control complementaria de la financiera, y separada solo por esa tenue línea que no constituye una delimitación tajante, sino una frontera dúctil que permite una clasificación elástica de las funciones del Legislativo donde unas y otras comparten determinadas notas.

\section{A. El Paquete económico}

Una de las facultades más importantes que tienen los parlamentos es imponer contribuciones, fijar los gastos públicos y legislar en todo lo relacionado con la materia económica, “como órganos encargados de autorizar y fiscalizar el gasto de los recursos

\footnotetext{
15 Zagrebelsky, G., El derecho dúctil. La ley, derechos, justicia, Madrid, Trotta, 2002, p. 37.

${ }^{16}$ Ortega y Gasset, J., Discursos Políticos, Madrid, Alianza Editorial, 1974, p. 155.

17 Diccionario Universal de Términos Parlamentarios, op. cit., voz: financiera, función, Berlín Valenzuela, F., p. 429.
} 
públicos, [pues, valga] recordar que fue justamente dicha competencia la que fraguó el tránsito de las monarquías absolutas a las parlamentarias”" ${ }^{18}$.

La potestad tributaria, es decir, la suma de facultades del Estado para imponer contribuciones, encuentra su fundamento en el poder político que el pueblo ejerce por conducto de los entes públicos que este crea. En este caso, es el Poder Legislativo al que se ha otorgado la facultad de imponer contribuciones para cubrir el gasto público, en el que "imponer, significa tributo, carga, gravamen, contribución que gobierno exige"19. Los impuestos son de carácter público, pecuniario -y por excepción, en especie- obligatorios ex lege, conllevan una relación de derecho y obligación entre el Estado y el particular, su objetivo es que el Estado cuente con recursos para cumplir con sus funciones y deben ser proporcionados, equitativos y destinados al pago del gasto público ${ }^{20}$.

La suma de las contribuciones que el Estado está autorizado a recaudar en el periodo de un año se encuentra en la Ley de Ingresos, "sin que ello implique que las contribuciones establecidas en las leyes fiscales relativas, tengan vigencia de solo un año”, pues [...] “... las leyes de ingresos no constituyen sino un catálogo tributario, que condicionan la aplicación de las referidas disposiciones impositivas de carácter oficial, pero que no renuevan la vigencia de estas últimas, que deben estimarse en vigor desde su promulgación, en forma ininterrumpida, hasta que son derogadas”21.

Por su parte, "gasto público es toda erogación que realiza el Estado para efectuar sus fines y sostener su estructura, los recursos que emplea provienen de las contribuciones que le dan los ciudadanos a través de los impuesto, el cual debe ser distribuido de manera adecuada, a efecto de cubrir las necesidades propias del Estado y las sociales; por ello, la formulación del gasto público tiene que manifestar objetivos, metas, costos y órganos responsables" ${ }^{22}$, lo cual servirá para efectos de su adecuada fiscalización y la evaluación de la gestión financiera. El gasto público también es determinado para ejercicios anuales y su monto total debe corresponder a los ingresos previamente autorizados.

En México, el denominado “paquete económico” incluye la Ley de Ingresos como el Presupuesto de Egresos, entre otros ordenamientos, los cuales tienen el propósito de satisfacer las necesidades de la sociedad, mediante la funcionalidad del gobierno, entendido como la suma de todos los entes públicos que forman parte de los poderes del Estado, o bien cuya existencia se origina por mandato constitucional.

Mediante el desarrollo de su función financiera, el Poder Legislativo se relaciona con el quehacer de todas las autoridades, no solo por la aprobación de las contribuciones que algunas de ellas pueden cobrar o por la vía de la autorización del presupuesto para cada año de ejercicio, sino también con la emisión de Ieyes para regular las funciones

\footnotetext{
18 Mora-Donatto, C., Instrumentos Constitucionales para el control parlamentario, Revista Mexicana de Derecho constitucional, núm. 4, enero-junio de 2001, Instituto de Investigaciones jurídicas de la UNAM, pp. 85-113, p.101, en http://www.jurídicas.unam.mx/publica/rev/cconst/4/art/art4.htm.

${ }^{19}$ Diccionario Universal de Términos Parlamentarios, op. cit., voz: impuestos, Namorado Urrutia, P., p. 476

${ }^{20}$ Ibidem, pp.447-478.

${ }^{21}$ Idem.

${ }^{22}$ Idem, voz gasto público, Berlín Valenzuela, F., p. 446.
} 
económicas del Estado, como las que este ejerce de manera exclusiva en áreas estratégicas, como previene el artículo 28 constitucional. Este poder colegiado también puede autorizarle al Ejecutivo contraer deuda pública y mandar pagarla, para realizar cierto tipo de inversiones; también tiene a su cargo la expedición de leyes sobre planeación nacional del desarrollo económico y social, así como para la programación, promoción, concertación y ejecución de acciones de orden económico; para determinar la intervención del Estado en materia de prácticas comerciales entre entidades de la república; para legislar en materia de hidrocarburos, minería, industria cinematográfica, comercio, juegos con apuestas y sorteos, intermediación y servicios financieros, sociedades cooperativas, energía eléctrica y nuclear, tabacos labrados, cerillos y fósforos, aguamiel, cerveza, o explotación forestal; legislar en materia de servicios públicos concesionados o explotados directamente por la federación; para crear y suprimir empleos públicos de la misma.

\section{La función de control}

Para contener al poder político, afirma Karl Lowenstein ${ }^{23}$, es preciso restringirlo, limitarlo, lo que se ha logrado mediante la Constitución, de ahí que la función de control se considere una de las características más importantes del estado democrático de derecho.

Para efectos de esta función, interesa el control que ejerce el Congreso y que tiene que ver con elementos como "inspección, fiscalización, comprobación, revisión o examen que lleva a cabo el Parlamento sobre la actividad que realiza el Ejecutivo, con la finalidad de verificar ajusta sus actos a las disposiciones establecidas en la ley”24.

La función de control a cargo del Legislativo tiene como finalidad evitar que los poderes abusen de sus facultades, principalmente el Ejecutivo, y se extralimiten en perjuicio de sus pares y de los gobernados, las características que identifican a las funciones de control que corresponde realizar al Parlamento, se han transformado de manera radical y en la actualidad sirven a objetivos diversos, tanto de control, sanción o censura, como de información para el análisis de las políticas públicas, así en la autorización de recursos presupuestales para su implantación como para la introducción de correctivos durante dicho proceso, conforme al caso.

Diego Valadés afirma que "la aplicación más sencilla de las formas de control parlamentario [...] facilitaría la relación entre el Congreso y el gobierno porque, sin poner en riesgo su estabilidad, ofrecería a las fuerzas políticas opositoras la oportunidad de hacer valer sus razones acerca de la conducción del país”25.

En todo caso, un adecuado desarrollo de la función de control permitirá el establecimiento de relaciones de corresponsabilidad entre los poderes, y de estos con la sociedad.

\footnotetext{
${ }^{23}$ Lowenstein, K., cit. pos. Huerta Ochoa, C., Mecanismos constitucionales para el control del poder político, $3^{\mathrm{a}}$ ed., México, UNAM, 2010, p. 103.

${ }^{24}$ Berlín, op. cit., p. 139.

${ }^{25}$ Valadés, D., La parlamentarización de los sistemas presidenciales, 2ª ed., México, UNAM, El Colegio Nacional, 2008, pp. 222-223.
} 
La función de control debe ser de tracto sucesivo y realizarse, en esencial, por medio de dos vertientes:

a) control político, mediante mecanismos diversos, como las comparecencias de servidores públicos del Ejecutivo para informar; la constitución de comisiones de investigación: el juicio de responsabilidad política contra funcionarios de alta jerarquía: o la ratificación de nombramientos, actos y tratados internacionales; $\mathrm{y}$

b) control económico, por la de revisar la cuenta pública, resultado de la aplicación de los ingresos y egresos que aprueba el Congreso en ejercicio de su función financiera.

\section{A. Control político}

Los controles políticos guardan una íntima relación con las diferencias que presentan cada una de las funciones de los órganos del Estado, de forma tal que esta, no es exclusiva del Congreso; con base en la teoría de pesos y contrapesos, el control es una función que realizan todos los órganos del poder público y cada uno de ellos deben ser controlados por un poder distinto. Un acto político goza de mayor legitimidad cuando en su creación o elaboración participan diversos tenedores de poder, ya que los intereses que cada uno representa son respetados y atendidos en función de un bien mayor o del bienestar general.

Los efectos del control político que ejerce el Congreso se dan desde el momento mismo del despliegue de la actividad, la cual pone de relieve que el ejercicio del poder público está siendo fiscalizado y controlado, ya que las actividades que realizan las instancias gubernamentales no pueden sustraerse a la crítica institucional que aquel realiza.

\section{B. Juicio político}

El fincamiento de la responsabilidad política tiene su origen en el impeachment inglés, institución surgida en el siglo XVII; la monarquía inglesa al verse obligada a ceder ámbitos de poder a favor del parlamento dio lugar a una serie de relaciones basadas en un régimen de competencias, de coordinación y sujeción a límites y controles mutuos que originaron el parlamentarismo ${ }^{26}$.

El rechazo a este nuevo sistema de gobierno por parte del rey Carlos I (cabeza de un gobierno absolutista y tiránico, señalado por su voraz apetito recaudador) le llevó no solo a enfrentarse al Parlamento, sino a prescindir de él durante periodos prolongados, lo que le condujo a una literal sentencia de muerte dictada por el parlamento en su contra, en la cual se le consideró “tirano, traidor, asesino y enemigo del país”27.

\footnotetext{
${ }^{26}$ González Oropeza, M., “La responsabilidad política en el derecho constitucional mexicano”, pp. 459-483, en Anuario Jurídico XI 1984, México, UNAM, 1984 (Seminario de Actualización de la Legislación Mexicana 1976-1982). Véase en particular el inciso I. Antecedentes ingleses.

${ }^{27}$ Berlín, op. cit., p. 166.
} 
En la actualidad, se trata de un mecanismo mediante el cual el Legislativo realiza una función de control político sobre los servidores públicos de los tres poderes del Estado, así de la federación, como de las entidades federativas, a que se refiere el artículo 110 constitucional. Cada una de las cámaras del Congreso tiene una participación específica en el procedimiento para juzgar políticamente a dichos servidores públicos por los actos u omisiones que causen perjuicio a los intereses públicos fundamentales de la nación. Mientras la Cámara de Diputados conduce la instrucción para presentar eventualmente la acusación correspondiente, el Senado actúa como juzgador, es el que resuelve en definitiva, ya sea que determine la improcedencia de la acusación o dicte la sanción correspondiente, que puede consistir en la separación del cargo o en la prohibición para ocupar otro, además de la reprobación política. En el caso de los servidores públicos de las entidades federativas, el juicio político solo es procedente por violaciones graves a la Constitución y a las leyes federales, así como por el manejo indebido de fondos y recursos federales; la resolución tiene efectos meramente declarativos, por lo que toca a las legislaturas locales determinar el tratamiento que le darán.

\section{El informe del Ejecutivo y las comparecencias}

Se trata de un mecanismo de control político a posteriori, con base en el cual el Legislativo conoce la manera en que el primero ejerció las funciones que derivan del mandato constitucional y legal, incluido el ejercicio de los recursos públicos, si bien la revisión formal de la cuenta pública y la evaluación de la gestión financiera, la realiza la Cámara de Diputados por conducto de la entidad superior de fiscalización.

El control que ejerce la representación popular sobre el desempeño de la administración pública federal es de carácter político, en atención a la naturaleza del órgano revisor y al aspecto revisado, además de que de este se pueden derivar otros actos de control, como el de la responsabilidad política, por ejemplo. Este acto tiene también un gran impacto político en la sociedad, en tanto sirve a los gobernados para expresar rechazo o aprobación a sus gobernantes mediante el ejercicio del sufragio.

La ceremonia del informe, cuyo formato ha regulado la normativa secundaria, transitó por escenarios extremos: de la apología del presidente, hasta la del enfrentamiento directo, por la que un levantisco grupo de legisladores impidió su ingreso al salón de sesiones. También ha dado lugar a intensos debates entre fuerzas políticas antagónicas que consideran, por un lado, que el formato debe incluir mecanismos para la deliberación entre uno y otro poder en la misma fecha de presentación del informe, del otro lado están las que consideran que el intercambio de puntos de vista y la posibilidad de ampliar la información debe darse en otro momento, durante el periodo de su glosa.

De acuerdo con Eliseo Muro "lo que busca el sistema de rendición de cuentas del nuevo formato presidencial como un esquema de control parlamentario, es fiscalizar y controlar las áreas de la administración pública, con el fin de evidenciar sus errores por acción u omisión” ${ }^{28}$, postura al parecer no es del todo atinada, ya que el informe

\footnotetext{
${ }^{28}$ Muro Ruiz, E., El nuevo formato del informe presidencial, un instrumento de control parlamentario en México”, Homenaje al Doctor Emilio O. Rabasa, México, UNAM, 2010, p. 351.
} 
presidencial es también un mecanismo para fortalecer el diálogo republicano entre los poderes Legislativo y Ejecutivo, y la responsabilidad de ambos en la toma de decisiones trascendentes.

\section{Comisiones de investigación}

Dentro de los mecanismos de control parlamentario sobre el ejercicio del poder público se encuentran las comisiones de investigación, cuyo objetivo fundamental es indagar en determinados aspectos de la actividad gubernamental, cuando se tienen indicios de un desempeño inadecuado de las tareas encomendadas a las entidades públicas sujetas a este tipo de control. Las comisiones de investigación están integradas por un:

[...] grupo de legisladores que autorizados por su Cámara, en ejercicio de funciones constitucionales de control y vigilancia sobre actos del ejecutivo, realizan todas las diligencias necesarias para averiguar si los titulares de los órganos del ejecutivo han o no incurrido en cualquier tipo de responsabilidad ya sea, por incumplimiento en efecto o en exceso o por violación o infracción a las leyes que regulan su competencia y autoridad; o si cumplen o no sus programas y actividades dentro de la normatividad aprobada por el propio Poder Legislativo ${ }^{29}$.

Con la adición del párrafo tercero al artículo 93 constitucional, llevada a cabo a finales de 1977, se estableció como facultad del Legislativo la de integrar comisiones para investigar el funcionamiento de los organismos federales descentralizados y de las empresas de participación estatal mayoritaria. Una de las principales motivaciones de dicha reforma fue la existencia, en ese entonces, de casi 900 entidades de esta naturaleza.

La cifra se ha reducido en forma significativa, resultado de los procesos de desincorporación del sector público que de tales entidades ocurrieron a lo largo de los últimos lustros; sin embargo, la importancia que reviste la existencia de límites y controles al ejercicio del poder público ha permitido no solo que dicha facultad se haya conservado en nuestro texto constitucional, sino que se haya generado en torno suyo un importante debate acerca de la necesidad de fortalecerla, mediante la ampliación del ámbito competencial de las comisiones investigadoras a todos los sujetos fiscalizables, y hacer que el resultado de sus investigaciones se convierta en un indicio suficiente para que el Ministerio Público inicie las averiguaciones que correspondan.

\section{E. Nombramientos y ratificaciones}

La inicial facultad exclusiva del Senado para ratificar a ministros, cónsules y agentes diplomáticos, empleados superiores de Hacienda y algunos cargos militares, que tenía escasa relevancia en términos del ejercicio del poder público, fue ampliando sus linderos y con ellos la relación con otros órganos del poder público, hasta convertirse en una facultad importantísima de las cámaras del Congreso que hoy exige, según el

\footnotetext{
${ }^{29}$ Diccionario Universal de Términos Parlamentarios, op. cit., voz: comisiones de investigación, Camposeco Cadena, M.Á., p. 198.
} 
nombramiento de que se trate, de procedimientos ad hoc y el concurso de otras instancias gubernamentales.

En el caso del Senado, además de la ratificación de los nombramientos señalados, se incluyó la del procurador general de la República (PGR), ahora fiscal general de la República, y por una reforma constitucional reciente, en adelante le corresponderá también la de los integrantes de las comisiones federales de telecomunicaciones, de energía y de competencia económica. Es competencia también de esta cámara, la designación de los ministros de la Suprema Corte, de entre la terna que someta a su consideración el titular del Ejecutivo, así como la de otorgar o negar su aprobación a las solicitudes de licencia o renuncia de estos. Las ratificaciones y designaciones están sujetas al procedimiento que determina la ley.

La Cámara de Diputados, por su parte, está facultada para elegir a los integrantes del Consejo General del INE, a propuesta de los grupos parlamentarios, previa realización de una amplia consulta a la sociedad, y mediante el voto de las dos terceras partes de los miembros presentes.

\section{F. Cuestión política}

El término "cuestión política” fue importado de la legislación norteamericana e incorporado a nuestro texto constitucional. Su alcance no se fijó en la resolución de una situación de carácter político cualquiera, sino en una facultad del Senado para atender y, de manera eventual, dar solución a las cuestiones derivadas de conflicto entre poderes de un estado, en tanto existían dudas sobre la competencia de la Suprema Corte en esa materia. En el siglo XVIII, en México se reconocía que los jueces, incluidos los del máximo tribunal, no tenían la capacidad para resolver un conflicto de esta naturaleza sin la normatividad adecuada.

Este procedimiento tiene una naturaleza singular nada común, ya que no es estrictamente jurisdiccional por el carácter político del órgano que conoce: el Senado, el cual no busca coadyuvar al entendimiento de las partes, sino resolver la cuestión con la potestad de su autoridad. Tampoco se trata de un procedimiento heterocompositivo, porque la sujeción de los poderes en conflicto a la decisión del Senado no es voluntaria, sino obligatoria. Rubén Sánchez $\mathrm{Gil}^{30}$ considera que el procedimiento senatorial es auxiliar y subsidiario del jurisdiccional, ya que siempre estará expedita la vía para que la Corte pueda conocer la impugnación que de la resolución senatorial eventualmente se haga, supuesto en el cual se estaría en posibilidad de conocer el fondo del asunto. Por ello, de acuerdo con este autor, el procedimiento no es jurisdiccional ni heterocompositivo, es sencillamente sui generis.

G. Desaparición de poderes en los Estados

\footnotetext{
${ }^{30}$ Sánchez Gil, R., Funciones y alcances del Procedimiento senatorial de solución de "Cuestiones Políticas” Obra de acervo de la Biblioteca Jurídica Virtual del Instituto de Investigaciones Jurídicas de la UNAM, en http://biblio.jurídicas.unam.mx/libros/7/3047/18.pdf, [consultado 19/6/2012].
} 
Se trata de una facultad que se inserta en el catálogo de las constitucionales a favor de los poderes federales, contenida en la fracción V del artículo 76 constitucional, y su objetivo es que el Senado le haga frente a un eventual vacío de poder, de una o más de las partes integrantes de la federación.

V. Declarar, cuando hayan desaparecido todos los poderes constitucionales de una entidad federativa, que es llegado el caso de nombrarle un titular del poder ejecutivo provisional, quien convocará a elecciones conforme a las leyes constitucionales de la entidad federativa. El nombramiento del titular del poder ejecutivo local se hará por el Senado a propuesta en terna del Presidente de la República con aprobación de las dos terceras partes de los miembros presentes, y en los recesos, por la Comisión Permanente, conforme a las mismas reglas. El funcionario así nombrado, no podrá ser electo titular del poder ejecutivo en las elecciones que se verifiquen en virtud de la convocatoria que él expidiere. Esta disposición regirá siempre que las constituciones dc las entidades federativas no prevean el caso ${ }^{31}$.

Esta facultad ha merecido críticas variadas que consideran va en desmedro del federalismo; sin embargo, consideramos que una de las características del Estado federal consiste en que las entidades que lo componen, ceden parte de su soberanía a la federación, de ahí que corresponda a esta última la obligación de velar por la seguridad y promover el desarrollo armónico de las primeras, situación que beneficia a unos y otros, además de que el ejercicio de dicha facultad nunca dejará de ser una medida extraordinaria para hacer frente a una situación extraordinaria.

\section{H. Tratados internacionales}

Se entiende por "tratado" un "acuerdo internacional celebrado por escrito entre Estados y regido por el derecho internacional, ya conste en un instrumento único o en dos o más instrumentos conexos y cualquiera que sea su denominación particular” ${ }^{32}$, incluidos los que se celebren, en el caso de nuestro país, con organizaciones internacionales. Si se toma en cuenta que dichos instrumentos forman parte preponderante del sistema jurídico mexicano, la intervención del Senado tiene tal relevancia, que rebasa la de su mera ratificación. Como lo expresa Javier Ruipérez Alamillo “esta función tiene la influencia del Derecho Constitucional Estadounidense y se presenta como lo que Antonio La Pergola llama "Residuo Contractualístico", es decir una decisión adoptada por el Legislador Constituyente libremente, pero condicionado por lo que sucedía en la situación jurídica anterior: la Confederación. Y es que el Senado estadounidense tiene atribuida esta función por ser el heredero directo del Congreso Confederal, en cuanto que único órgano de la Unión y en el que estaban representados, y hacían valer la voluntad de éstos, los Estados particulares como únicos sujetos de la unión confederal”33.

\footnotetext{
${ }^{31}$ Artículo 76, fracción V, Constitución Política de los Estados Unidos Mexicanos, op. cit., [consultado 24/1/2018].

32 Artículo 2, inciso a), de la Convención de Viena sobre el Derecho de los Tratados de 1969, en http:// www.derechos.org/nizkor/ley/viena.html,[consultado 19/7/2012].

${ }_{33}$ Ruipérez Alamillo, J., Reforma constitucional y supresión del senado como cámara de representación territorial, México, Porrúa, 2018, pp. 253-254.
} 
En efecto, la facultad del Senado de "aprobar los tratados internacionales y convenciones diplomáticas que celebre el Ejecutivo de la Unión”, así como la de “avalar” la decisión de este último de "terminar, denunciar, suspender, modificar, enmendar, retirar reservas y formular declaraciones interpretativas sobre los mismos”, prevista en la fracción I del artículo 76 constitucional, tiene un alcance muy reducido, puesto que aquel no participa en el proceso de su negociación antes de ser aprobado, máxime si se considera que la Suprema Corte ha emitido el criterio de que los tratados internacionales se ubican jerárquicamente por encima de las leyes federales ${ }^{34}$, y que, por ende, algunos de estos llegan inclusive a vulnerar la soberanía de los estados, con modificaciones que impactan su régimen jurídico interior, es decir, su soberanía, reconocida de manera expresa y plena en la Constitución.

\section{Otros mecanismos de control político}

Algunas otras facultades del Congreso y de las cámaras pueden estar dentro de la clasificación de control político, puesto que se trata de la acción que realiza el primero sobre el titular del Ejecutivo cuando este ejerce una facultad que le es propia. Es el caso de la autorización que este requiere, de acuerdo con el artículo 29 constitucional, para restringir o suspender en todo el país, o en un lugar determinado, las garantías individuales, "en casos de invasión, perturbación grave de la paz pública, o de cualquier otro que ponga a la sociedad en grave peligro o conflicto".

Igual ocurre con la autorización que el Senado otorga al presidente de la República para: a) permitir la salida de tropas nacionales fuera del país, b) el paso de tropas extranjeras por nuestro territorio, c) la estancia de naves de otro país en aguas mexicanas; d) disponer de la Guardia Nacional fuera de sus respectivos estados; e) aprobar el reconocimiento que haga el Ejecutivo federal de la jurisdicción de la Corte Penal Internacional.

\section{J. Control económico}

La función de control económico que realiza el Congreso está ligada irremediablemente a los recursos del Estado, tanto en lo concerniente a los ingresos como a los egresos, la manera en que los primeros son recaudados y los segundos son ejercidos.

Es una derivación de la función financiera, forma parte de esta; sin embargo, en términos estrictos, el control económico tiene que ver más con una tarea de carácter reactivo, de evaluación de la gestión y ejercicio de los recursos públicos; este control puede analizarse desde dos puntos de vista distintos: a) el del órgano u órganos responsables de dicha actividad y b) el de las características que debe revestir la función, es decir, los objetivos, alcances y momentos de su realización, entre otros.

K. Evaluación de la gestión financiera

\footnotetext{
${ }^{34}$ Tesis P. LXXVII/99, Semanario Judicial de la Federación y su Gaceta, Novena Época, t. X, noviembre 1999, p. 46.
} 
La evaluación de la gestión financiera constituye una de las actividades más destacadas y trascendentales que realizan los parlamentos en el contexto de los estados democráticos de derecho; su importancia está por encima del apoyo técnico que requiere el órgano del Estado titular de la misma para ejercerla a cabalidad, aunque sin demérito de la actividad de este último.

En nuestro país, la facultad de control de la gestión financiera es exclusiva de la Cámara de Diputados de acuerdo con lo previsto por los párrafos quinto y sexto de la fracción IV del artículo 74 constitucional, los cuales establecen que corresponde a esta revisar y, en su caso, aprobar la cuenta pública, para lo cual "se apoyará en la Entidad de Fiscalización Superior de la Federación”. En otras palabras, para que la primera esté en posibilidad de cumplir con su función de fiscalización, requiere en el "diagnóstico" que lleve a cabo la segunda, en el trabajo técnico de análisis del ejercicio del gasto público. Esta actividad de carácter técnico no puede sobreponerse, en modo alguno, a la función de carácter político relativa al control de la gestión financiera. Es más, debe entenderse que la primera es accesoria de la segunda, si nos atenemos a lo estipulado por la fracción II del propio artículo 74, que faculta a la Cámara de Diputados para "Coordinar y evaluar, sin perjuicio de su autonomía técnica y de gestión, el desempeño de las funciones de la entidad de fiscalización de la Federación, en los términos que disponga la ley”.

Previo al establecimiento constitucional de una entidad de fiscalización se creó la Contaduría Mayor de Hacienda, dependiente de la Cámara de Diputados, con lo que se agotaba el objetivo de conservar a dicho órgano de vigilancia al margen de los cambios en esta última, hasta el 2000, año en que se crea la Auditoría Superior de la Federación (ASF). Esta fue facultada para la cuenta pública y evaluar la gestión financiera, es decir, la administración, manejo, custodia y aplicación de los recursos públicos, a fin de verificar que dicha gestión se ajustara a las disposiciones legales, reglamentarias y administrativas aplicables, así como al cumplimiento de los programas.

La fiscalización se ejerce sobre todas las entidades, organismos y dependencias de la administración pública federal, estatal y municipal y sobre particulares que ejerzan recursos federales. Tiene por objeto determinar si los programas y su ejecución se ajustan a los términos y montos aprobados; si los ingresos y egresos se ajustan a las partidas respectivas; si el cumplimiento de los programas se ha hecho con eficiencia y economía, con base en los indicadores aprobados en el presupuesto; si los recursos se obtuvieron en los términos autorizados y con base en eso determinar los daños y perjuicios que eventualmente hayan afectado a la hacienda pública federal; así como determinar las indemnizaciones y las sanciones pecuniarias que correspondan.

Por otra parte, es obligación de la ASF ser promotora de la transparencia, eficiencia y mejora continua de los servicios públicos, garante, ante el Poder Legislativo y la sociedad, de que los recursos del pueblo son recaudados, administrados y aplicados con honestidad, economía y eficiencia, y apoyar a las instancias gubernamentales en la solución de problemas estructurales y en la identificación de oportunidades de mejora de las instituciones públicas, bajo los principios de profesionalismo, objetividad, imparcialidad, honestidad, confiabilidad, responsabilidad e integridad. 


\section{Funciones de carácter instrumental}

Estas no son funciones parlamentarias en sí mismas, sino que son complementarias o necesarias para que el Congreso y cada una de sus cámaras estén en posibilidad de cumplir con sus funciones y ejercer sus facultades a plenitud. Sin los mecanismos e instrumentos necesarios para tal propósito, no podrían lograr suficientemente su cometido.

Su finalidad es la de coadyuvar a la realización de las distintas actividades que se relacionan con las funciones del Congreso y de las cámaras. Sin un proceso deliberativo previo, por ejemplo, no sería posible conocer el posicionamiento político u opinión de los legisladores respecto de una iniciativa, una proposición, una solicitud de otro poder o de particulares o cualquier otro asunto sometido a su consideración. Sin las tareas que llevan a cabo las áreas administrativas, no podrían funcionar los distintos órganos camarales: a) las comisiones, b) los comités, c) el Pleno, d) la Mesa Directiva, e) la Jucopo, etcétera; y sin la normativa adecuada para desahogar diferentes procedimientos, quedarían sin posibilidad de ser desahogado el juicio político o la remoción de la inmunidad constitucional, o la realización de diversas tareas que se rigen bajo el conjunto de normas emitido por ambas cámaras, en ejercicio de las facultades que les otorga el artículo 77 constitucional.

Las funciones instrumentales del Congreso no resuelven necesidades de la sociedad, sino de las cámaras, para que ambas estén en posibilidad de cumplir con aquellas que sí atienden asuntos de interés general. Entre ellas se encuentran: a) la deliberativa, b) la jurisdiccional, y c) la parlamentaria administrativa, que a continuación se comenta.

\section{A. La función deliberativa}

Deliberar - vocablo latino compuesto por el prefijo de y el verbo librare, significa "pesar en una balanza" - implica valorar los pros y los contras de una decisión antes de emitir una postura, declaración, sentencia o un voto. "Los cuerpos colegiados desarrollan muchas de sus facultades a través de deliberaciones; es decir, a través de discusiones donde se valoran las distintas posiciones que ofrecen un problema o un asunto”35. Así, esta función del Legislativo se sintetiza en el proceso de valoración que realizan los legisladores sobre las implicaciones, ventajas y desventajas, en este caso, de las iniciativas, proyectos o dictámenes que son sometidos a su consideración para estar en condiciones de votar. Para ejercer adecuadamente esta función, los legisladores deben allegarse la información necesaria, también su función de inspección e indagación.

Toda reunión de personas para deliberar, tiene por lo menos dos posturas distintas, de ahí que esta función se sustente en la confrontación principio fundamental para la democracia, que es conducida bajo reglas determinadas de manera previa para la toma de decisiones. Para que una deliberación rinda los frutos esperados, es indispensable que se someta a "reglas de debate y es un proceso racional, pues ayuda a una asamblea a considerar y a convencer sobre los argumentos que apoyan para aprobar o desechar un

\footnotetext{
${ }^{35}$ Diccionario Universal de Términos Parlamentarios, op. cit., voz: deliberativa, función, González Oropeza, M., p. 328.
} 
punto de acuerdo, un decreto o una ley”36. Es decir, la confrontación de ideas entre grupos antagónicos que resisten a su oponente, tiene lugar dentro de los cauces institucionales y, conforme a Jesús Reyes Heroles, "lo que resiste apoya” ${ }^{37}$ y sin duda alguna, una resistencia apoya el avance político.

Las proposiciones con punto de acuerdo son utilizadas por los legisladores para plantear al Pleno determinados asuntos políticos, económicos, sociales, culturales, etcétera, los que en términos generales, forman parte de la agenda política acordada por los grupos parlamentarios, o bien, surgen supervenientemente y se relacionan por lo general con temas coyunturales que se consideran importantes.

Su objetivo es que la cámara a la cual le fue planteada la proposición emita un pronunciamiento político al respecto, el cual, bajo la forma de punto de acuerdo, puede consistir en la emisión de opiniones, recomendaciones o exhortos a otro poder del Estado, a los organismos constitucionales autónomos, a los poderes de las entidades federativas o a uno de ellos, para realizar, dar celeridad o suspender determinada actividad, mismas que no tienen efectos vinculantes.

Cuando es el caso de que las proposiciones sean consideradas como de urgente u obvia resolución, no son turnadas a comisiones para su dictamen, sino que son discutidas y votadas en asamblea enseguida de su presentación para después ser comunicadas a la instancia correspondiente. En el caso específico de las proposiciones con punto de acuerdo, la función deliberativa cobra una señalada relevancia.

La tendencia de los parlamentos en el ejercicio de su función deliberativa es que la discusión se lleve a cabo en los grupos más pequeños, como comisiones y comités, en las que se promueve la especialización en el conocimiento y la discusión informada de algunos temas.

\section{B. La función jurisdiccional}

El Legislativo realiza, de facto, una función jurisdiccional para calificar la responsabilidad política, en los términos del título cuarto de la Constitución que establece cuáles servidores públicos están sujetos al régimen de responsabilidades, la forma en que puede hacérseles exigible y los órganos de gobierno encargados de su aplicación, así como el procedimiento a seguir.

Son dos los casos en que el Legislativo ejerce la función jurisdiccional: la declaración de procedencia y el juicio político. El primero “es llamado, asimismo, ‘antejuicio' o ‘juicio de procedencia’, precisamente porque su propósito es la eliminación del obstáculo que significa el fuero, para que el alto funcionario o servidor público pueda

\footnotetext{
${ }^{36}$ Ibidem.

${ }^{37}$ Reyes Heroles, J., “El PRI está luchando contra los cacicazgos” discurso pronunciado el 6 diciembre de 1972, Obras completas, Eugenia Meyer (coord.), México, Asociación de Estudios Históricos y Políticos, Jesús Reyes Heroles, A.C., Secretaría de Educación Pública, FCE, t.III,1996, pp. 730-731.
} 
ser consignado ante los tribunales ordinarios”38. Se trata de una garantía de inmunidad procesal que tienen determinados servidores públicos, de acuerdo con el artículo 110 constitucional, cuando son acusados penalmente, si bien [...] la responsabilidad penal no se prueba con la aceptación de declarar la procedencia por parte de la Cámara de Diputados, sino que esta acción constituye tan sólo la verificación de que los hechos imputados presumiblemente inculpan al servidor público y de que las etapas de la procuración de justicia han sido debidamente conducidas sin privar al servidor de sus garantías ${ }^{39}$.

La declaración de procedencia “constituye un decreto de la Cámara de Diputados que afecta la situación de un servidor público, suspendiéndolo de su función y sometiéndolo a la autoridad del juez de distrito en materia penal que conoce del asunto"40. Debe entenderse que la inmunidad procesal no constituye una garantía de inimputabilidad penal para determinados servidores públicos, sino "una garantía constitucional de seguridad en el desempeño de su función y una protección al cargo público, por lo que la Suprema Corte de Justicia no lo ha considerado como un derecho personal renunciable por parte del servidor" ${ }^{41}$.

En el caso del juicio político, como ya se advirtió, corresponde a la Cámara de Diputados instaurar la etapa de instrucción, mientras que el Senado tiene la facultad de sentenciar, de acuerdo con la fracción VII del artículo 76.

\section{La función Parlamentaria administrativa}

Las funciones que realizan de manera cotidiana las cámaras del Congreso, en cumplimiento de las atribuciones que les competen, como ya se vio, pueden verse desde diferentes enfoques, según el objetivo que cumplen, la necesidad que satisfacen, la naturaleza del órgano que las realiza, etcétera.

La función se analiza en este apartado es de carácter instrumental y tiene que ver con todas aquellas actividades necesarias para el óptimo funcionamiento de las cámaras. En el desarrollo de la función parlamentaria administrativa puede haber o no componentes políticos, pero, realizadas por las cámaras o por un órgano parlamentario determinado, comparten esta última característica. En este sentido, dentro de la función parlamentaria administrativa podrían considerarse:

a) Las actividades que realizan las cámaras y que, siendo de naturaleza política, tienen solo un impacto interno, por ejemplo, recibir del Consejo General del INE, las copias certificadas de las constancias de mayoría y de asignación de diputados o senadores de representación proporcional, o la de solicitar el auxilio de la fuerza pública para salvaguardar el recinto parlamentario;

\footnotetext{
${ }^{38}$ Diccionario Universal de Términos Parlamentarios, op. cit., voz: juicio político, Namorado Urrutia, P., p. 546.

${ }^{39}$ Ibidem, voz: declaración de procedencia, González Oropeza, M., p. 319.

${ }^{40}$ Idem.

${ }^{41}$ Idem.
} 
b) Las que realizan los órganos camarales, como el Pleno, las comisiones, los comités, los grupos parlamentarios, la Mesa Directiva o la Jucopo, y que, por ser de naturaleza política, sirven a un propósito solo administrativo, como remitir los expedientes con dictámenes aprobados a la colegisladora, llevar el registro de las iniciativas y dictámenes que conocerá la cámara, así como de las leyes y decretos aprobados; o bien hacer la citación a las sesiones de cada cámara o de Congreso General;

c) Las que por ser de naturaleza administrativa tienen que ver con el desempeño de funciones políticas, como la aplicación de sanciones a los legisladores por ausencias injustificadas, comprobar el quorum antes o durante el inicio de una sesión, o dar trámite a una solicitud de licencia de un legislador.

Estas actividades están regidas por diversa normativa, ya sea que esté involucrado el ejercicio de una facultad constitucional o legal, o bien se base en una regulación secundaria.

\section{CONCLUSIONES}

El Poder Legislativo, lo mismo en sistemas de gobierno de corte parlamentario que presidencial, tiene la delicada tarea de equilibrar, encauzar, fiscalizar y controlar el ejercicio del poder público de todos los depositarios del mismo, tanto de los demás poderes, como de los organismos constitucionales autónomos y aun de las autoridades de otros ámbitos de gobierno.

La elección popular de sus integrantes en sistemas democráticos robustos, y su composición plural y diversa, a semejanza de la colectividad de nuestro tiempo, proporciona al Legislativo, la legitimidad suficiente para ostentar la representación nacional.

Si bien es cierto que ortodoxamente su función primordial es la de legislar, que no es sino la expedición de normas generales, abstractas y obligatorias, también lo es que desarrolla otras tantas tareas de carácter financiero y de control, en el sentido más amplio.

El quehacer legislativo, estrictamente hablando, responde al imperativo de proporcionar seguridad jurídica a toda la sociedad: reconocer y garantizar el ejercicio de los derechos fundamentales, señalar con precisión las atribuciones de los entes públicos y organizar el gobierno y la administración, de modo que el estado de Derecho prevalezca.

Las de naturaleza financiera están relacionadas con la determinación de los ingresos y los egresos públicos, con su debido ejercicio mediante el gasto público y la fiscalización del mismo.

La función de controlar es variada, se relaciona con la revisión permanente de las actividades de los otros poderes, especialmente del Ejecutivo. Una variante importante y delicada de esta responsabilidad formalmente legislativa, aunque materialmente jurisdiccional, es la verificación del comportamiento legal y honrado de servidores públicos 
del mismo poder y de otros, con la posibilidad de imponer una sanción política o allanar el camino para el enjuiciamiento penal propiamente dicho, a cargo del Poder Judicial.

El parlamento moderno como órgano colegiado que refleja la complejidad de las sociedades contemporáneas, ha reivindicado y ampliado funciones, y se ha consolidado como una instancia democrática de deliberación. Es vital su fortalecimiento.

\section{FUENTES DE CONSULTA}

BADIA, M. C., Manual de ciencia política, España, Tecnos, 1999.

BERLÍN VALENZUELA, F., Diccionario universal de términos parlamentarios, M.A. Porrúa, 1998.

CÁMARA DE DIPUTADOS H. CONGRESO DE LA UNIÓN, Constitución Política de los Estados Unidos Mexicanos, 2017.

CARBONELL, M., Y SALAZAR, P., División de poderes y régimen presidencial en México, Universidad Nacional Autónoma de México, 2006.

CONVENCIÓN DE VIENA SOBRE EL DERECHO DE LOS TRATADOS, 1969.

GONZÁLEZ OROPEZA, M., La responsabilidad política en el derecho constitucional mexicano. En Seminario de Actualización de la Legislación Mexicana 1976-1982, Anuario Jurídico XI 1984, México, UNAM, 1984.

HAMILTON, A., MADISON, S. Y JAY, J. (s/f). El Federalista. Número 51. Recuperado de http://www.antorcha.net/biblioteca_virtual/derecho/federalista/51.html.

KELSEN, H., Esencia y valor de la Democracia, 2a ed., Colofón, México, 2004.

MORA-DONATTO, C. (2001), Instrumentos constitucionales para el control parlamentario. Cuestiones Constitucionales Revista Mexicana de Derecho Constitucional, 1(4). https://doi.org/10.22201/iij.24484881e.2001.4.5611.

MORA-DONATTO, C., Temas selectos de derecho parlamentario, Universidad Anáhuac del Sur, 2001.

MURO RUIZ, E., El nuevo formato del informe presidencial, un instrumento de control parlamentario en México. En Homenaje al Doctor Emilio O. Rabasa, México, UNAM, 2010.

OCHOA, C. H., Mecanismos Constitucionales para el Control Del Poder Político, Universidad Nacional Autónoma de México, Instituto de Investigaciones Jurídicas, 2010.

ORTEGA Y GASSET, J., Discursos políticos, Alianza Editorial, 1974. 
PÁEZ DÍAZ DE LEÓN, L., Pensamiento social británico: ensayos y textos, UNAM, 2003.

REYES HEROLES, J., El PRI está luchando contra los cacicazgos, Discurso pronunciado el 6 diciembre de 1972, Obras completas, Eugenia Meyer (coord.) presentado en Asociación de Estudios Históricos y Políticos, Jesús Reyes Heroles, A.C., Secretaría de Educación Pública, FCE, t. III, México, 1996.

ROUSEAU, J.J., Discurso sobre el origen de la desigualdad entre los hombres, Madrid, NoBooks Editorial, 1923.

ROUSEAU, J.-J., El Contrato Social, Grandes Pensadores, Barcelona, 2004.

RUIPÉREZ ALAMILLO, J., Reforma constitucional y supresión del senado como cámara de representación territorial, Editorial Porrúa, 2018.

SÁNCHEZ GIL, R. (s/f), Funciones y alcances del Procedimiento senatorial de solución de "Cuestiones Políticas". Recuperado de Biblioteca Jurídica Virtual del Instituto de Investigaciones Jurídicas la UNAM website: http://biblio.jurídicas.unam.mx/libros/7/3047/18.pdf.

Tesis P. LXXVII/9, Semanario Judicial de la Federación y su Gaceta § Novena Época, t. x. (1999).

SCHMITT, C., Sobre el parlamentarismo, Editorial Tecnos, 1996.

VALADÉS, D., La parlamentarización de los sistemas presidenciales, 2ª ed., UNAM, El Colegio Nacional, 2008.

ZAGREBELSKY, G., El derecho dúctil: ley, derechos, justicia, Trotta, 2002. 